\title{
Psychotherapy: A Way Forward to Improve the Quality of Life in Otalgia Patients
}

\author{
Salman Baig1, Sara Sadiq2 ${ }^{*}$ \\ ${ }^{1}$ Department of Otolaryngology, Bahria International Hospital, Karachi, Pakistan \\ ${ }^{2}$ Department of Physiology, CMH Institute of Medical Sciences, Bahawalpur, Pakistan \\ Email: drsalmanbaig@gmail.com, ^dr.sarabhatti@gmail.com
}

How to cite this paper: Baig, S. and Sadiq, S. (2019) Psychotherapy: A Way Forward to Improve the Quality of Life in Otalgia Patients. International Journal of Clinical Medicine, 10, 386-393.

https://doi.org/10.4236/ijcm.2019.107031

Received: June 14, 2019

Accepted: July 21, 2019

Published: July 24, 2019

Copyright () 2019 by author(s) and Scientific Research Publishing Inc. This work is licensed under the Creative Commons Attribution International License (CC BY 4.0).

http://creativecommons.org/licenses/by/4.0/

(c) (i) Open Access

\begin{abstract}
Introduction: Otalgia is not only an indicator of impact of disease but also impairs the daily activities and personal behaviors as is unpleasant and disturbing for the patient. It leads to decrease in functional status up to the complete disability. Nowadays the main focus of physician is to eradicate the disease or the symptoms, leaving behind the humanistic element. In diseased state, the most important point is to assess and improve the quality of life by using multidisciplinary approach. Objective: The objective is to assess the quality of life in patients having otalgia, due to any cause. Methodology: A descriptive cross sectional study was conducted by using modified form of WHOQOL-100 and COQOL. Data was accepted, if CFI was greater than 0.9. Qualitative data were presented as frequency and percentages and quantitative data as mean with standard deviation. ANOVA was used to assess the variations among groups. Change in behavior was assessed by using the Likert scale for each domain of WHOQOL and COQOL by a ten-point scale. Results: Majority of participants about $60.2 \%$ were male and were from the age group of 16 - 30 years. Most of the sample population were from lower socioeconomic class. Looking over the WHOQOL-100, higher score represented the higher quality of life. Variation among different socioeconomic status was non-significant for positive attitudes but was highly significant $(\mathrm{p}=0.0020)$ for negative attitudes. Analyzing the COQOL scoring system, higher score reported the worse symptoms. The patient with high COQOL showed strong correlation with poor WHOQOL-100 score that was $\mathrm{p}$ value $<0.001$. Conclusion: The current study highlights the need of multidisciplinary approach for the better management and improving the quality of life in patients with otalgia.
\end{abstract}

\section{Keywords}

Quality of Life, Otalgia, Reassurance, Psychotherapy, Multidisciplinary Approach 


\section{Introduction}

Looking over the cases in otolaryngology clinics, majority of the patients have presented with the complain of otalgia. Unfortunately, some of them having complain since months with frequent visits to general physician, who have found nothing wrong on examination. On the other hand, few of them having infection specially the otitis media or any other underlying pathology [1] [2] [3].

On the basis of cause, otalgia is classified into two that is primary or otogenic otalgia, mainly because of any of the ear pathology, and secondary or referred otalgia, that might be due to either dysfunction of temporomandibular joint or referred neck pain [2] [4] [5] [6].

Otalgia is not only an indicator of impact of disease but also impairs the daily activities and personal behaviors as is unpleasant and disturbing for the patient [5]. It leads to decrease in functional status up to the complete disability. Nowadays the main focus of physician is to eradicate the disease or the symptoms, leaving behind the humanistic element. In diseased state, the most important point is to assess and improve the quality of life by using multidisciplinary approach. The term "Quality of life" is defined as individuals' recognition of his position in life with reference to culture and values along with goals, expectations, standards and concerns. WHO had introduced a scoring system to assess the quality of life (WHOQOL-100) in diseased patients and to promote a holistic approach in health care system [7] [8]. Recently, an otology-specific questionnaire has been established, named as Cambridge Otology Quality of Life Questionnaire (COQOL), having excellent reliability and validity to assess the quality of life in otology clinics [9].

Few of the studies have been done to assess the quality of life specifically in the patients of otitis media but none of the study has been yet assessed the patients with otalgia, leaving behind underlying cause. So the objective of the current study is to assess the quality of life in patients having otalgia, due to any cause.

\section{Methods}

A descriptive cross sectional study was conducted on the patients presented with the history of ear pain. The data was collected from the out-patient department (OPD) of otolaryngology in the Dr. Ziauddin Hospital, Kemari Campus, Karachi during the month of June to August 2018. The study got approval from the Ethical review committee of Ziauddin University and Hospital. Convenience sampling technique was used for the selection of study participants and the consent was taken. A sample size of 216 patients was collected. Those participants were included in the study who had presented with complain of ear pain due to any underlying cause while those were excluded who either didn't give the consent or having language barrier or having concurrent illnesses that can affect the quality of life like severe heart or lung disease, etc. A modified form of WHOQOL-100 and COQOL was used. The questions including were about ear pain, its duration, involving site, vertigo, extent of hearing loss, patient's func- 
tional status and behavioral changes.

Data was accepted, if it was fit for the model in which the Comparative Fit Index (CFI) was greater than 0.9. Data analysis was performed by using 20th version of SPSS. Qualitative data were presented as frequency and percentages and quantitative data as mean with standard deviation. ANOVA was used to assess the variations among the groups while Post-Hoc Tukey's test was further applied to analyze the intragroup variations where applicable. P-value $\leq 0.05$ was considered as significant.

To measure the overall general health and quality of life WHOQOL-100 was analyzed by scoring the main domains including Physical, Psychological, Social Relationships and Environmental domain as mentioned in Figure 1.

Change in behavior either positive or negative was assessed by using the Likert scale $(1$ - 5) for each domain of WHOQOL, options including were not at all, a little, a moderate amount, very much and an extreme amount. The means of all the items of each domain was calculated and then multiplied by a factor of four, afterward transformed to a 0 - 100 scales by using the following formula:

TRANSFORMED SCORE $=(\operatorname{SCORE}-4) \times(100 / 16)$.

COQOL was analyzed to assess the intensity of the symptoms that affect the quality of life. For this purpose, a 10-point scale was used, starting from strongly disagree up to strongly agree. The total score of all points were 240 in which minimum score was an indicator of improved quality of life.

\section{Results}

About 216 patients were included in the study that was attended in outpatient department of Ziauddin Hospital. The majority of participants were male that was about $60.2 \%$ and were from the age group of 16 - 30 years while mean age of the participants were $26 \pm 8$. Looking over the socioeconomic status, most of the sample population were from lower class that was about $64.35 \%$. The main characteristics of study participants are mentioned in Table 1.

Looking over the WHOQOL-100, domain collectively scored 0 - 100 scales in positive direction, higher score represented the higher quality of life. Mean score for positive attitude among male was $37.55 \pm 4.51$ while among females was $32.84 \pm 3.08$, on the other hand considering negative attitude scenarios, the less score was reported among males that was $62.45 \pm 5.49$ and among females was $67.16 \pm 6.92$.

Variation among different socioeconomic status was non-significant for positive attitudes but was highly significant $(p=0.0020)$ for negative attitudes. The participants with lower socioeconomic status were presented with higher score for negative attitude. Duration of symptoms reported significant impact on both dropping in positive attitude while rise in negative attitude.

Analyzing the COQOL scoring system, higher score reported the worse symptoms. The patient with high COQOL showed strong correlation with poor WHOQOL-100 score that was $\mathrm{p}$ value $<0.001$. Hearing loss either unila- 
teral or bilateral was found to be a further decline in positive attitude with a mean difference of -6.17 , on the other hand for negative attitude a highly significant change was observed with mean difference of 5.8 indicating rise in negative attitude.

\section{Discussion}

Multidisciplinary approach is termed when health care providers of different specialties work collaboratively for the sake of improving quality of life in patients [10]. Current study shows higher percentage of males were affecting (60\%) that might be due to increase exposure to noise as compare to females. Out of total 216 patients, only $10.8 \%$ were younger than 15 years of age on the other
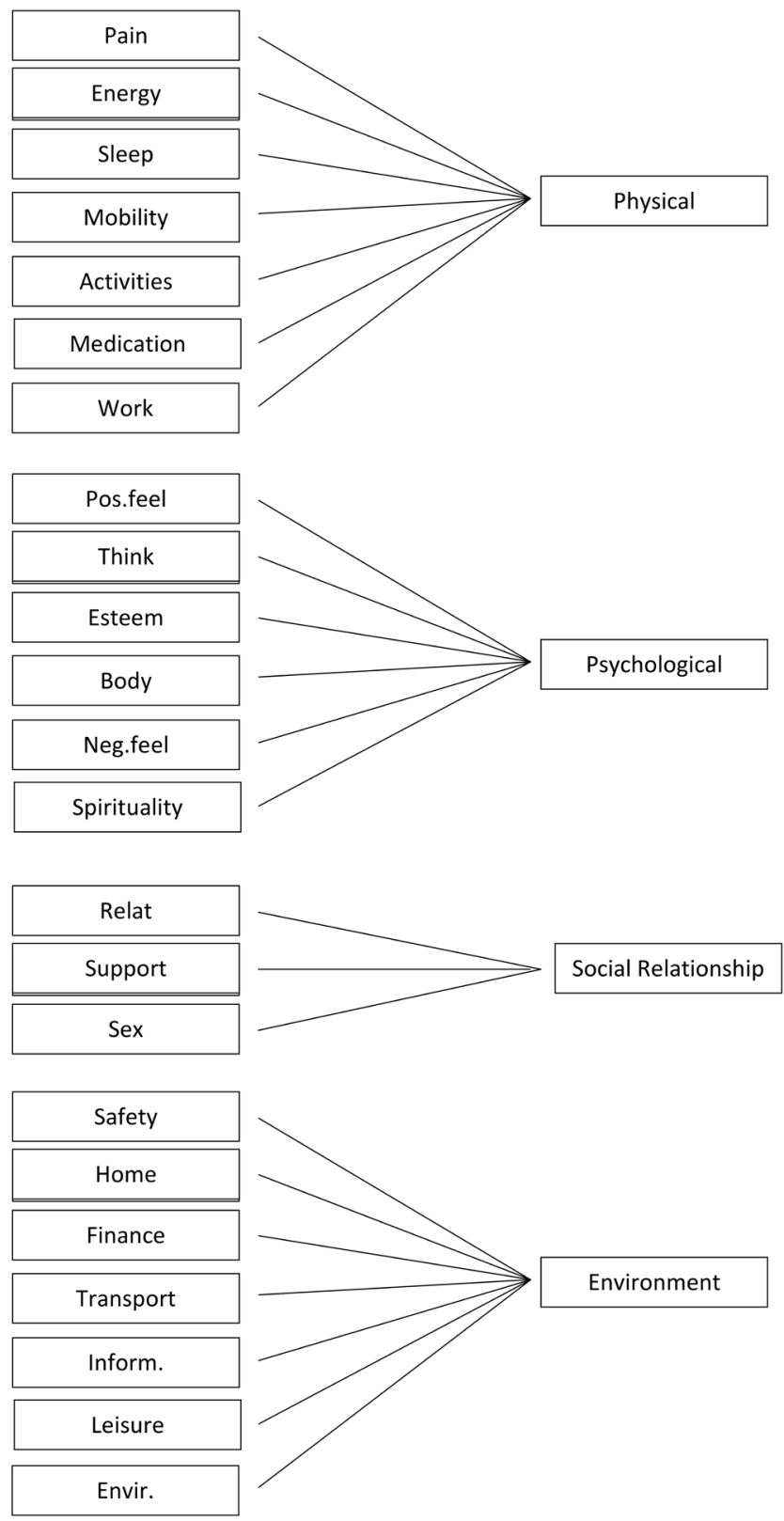

Figure 1. Items included in the four domain of the WHOQOL-100. 
Table 1. Characteristics of participants.

\begin{tabular}{|c|c|c|}
\hline & $\mathrm{n}$ & $\%$ \\
\hline \multicolumn{3}{|c|}{ Gender } \\
\hline Male & 130 & 60.2 \\
\hline Female & 85 & 39.4 \\
\hline \multicolumn{3}{|c|}{ Age } \\
\hline$<15 \mathrm{yr}$ & 23 & 10.8 \\
\hline $16-30 \mathrm{yr}$ & 87 & 40.3 \\
\hline $31-45 \mathrm{yr}$ & 62 & 28.5 \\
\hline $46-60 \mathrm{yr}$ & 27 & 12.1 \\
\hline$>61 \mathrm{yr}$ & 13 & 6.1 \\
\hline \multicolumn{3}{|c|}{ Socioeconomic Status } \\
\hline Upper class & 43 & 19.9 \\
\hline Middle class & 33 & 15.3 \\
\hline Lower class & 139 & 64.35 \\
\hline \multicolumn{3}{|c|}{ Site } \\
\hline Unilateral & 170 & 78.7 \\
\hline Bilateral & 46 & 21.3 \\
\hline \multicolumn{3}{|c|}{ Duration } \\
\hline$<7$ days & 152 & 15.170 .4 \\
\hline 7 - 30 days & 49 & 22.7 \\
\hline$>30$ days & 15 & 6.9 \\
\hline \multicolumn{3}{|l|}{ Hearing loss } \\
\hline Yes & 105 & 48.6 \\
\hline No & 109 & 50.5 \\
\hline
\end{tabular}

hand majority of the studies have been done on pediatric age group [11] [12] [13] [14]. The current study shows that the frequency of otalgia is significant among all age groups.

In current study about $48.6 \%$ of the patients with otalgia presented with hearing loss while a study done in Europe reported only $2.5 \%$ cases of hearing loss with otalgia [15]. On the other hand, a study conducted in South Korea supported our finding up to some extent, as they reported 35\% of hearing loss in otalgia patients [6]. These variations might be due to either late presentation of patients to the otolaryngology clinic or the misdiagnosis of root cause. Current study shows that majority of cases that is about $78.7 \%$ having unilateral otalgia and this finding is supported by another study having frequency of unilateral otalgia in about $83.7 \%$ [6].

Number of studies have been done to report either the influence of otitis media on the child's quality of life [11] [12] [13] [14] or quality of life after the tympanostomy tube insertion in child [16] [17] [18] or influence of chronic oti- 
tis media or surgery on the adult's quality of life [19] [20] [21]. To the best of our knowledge this is the first study which has been done to assess the quality of life in otalgia patients in order to highlight the need of multidisciplinary approach. The current study manifests that otalgia suppresses the quality of life so having higher ratio of negative attitude in otalgia patients which emphasize the need of reassurance and psychological support beside the medical treatment. As one of the study assessed the quality of life before and after management, they classified their study participants into groups on the basis of type of management given. Their results reported a highly significant association of improvement in the quality of life with the reassurance of patients beside medical therapy and surgical intervention. There are some of the conditions such as tinnitus or mild unilateral hearing impairment, that have no effective cure, so considering reassurance as the best strategy for these patients [22].

\section{Conclusion}

The current study highlights the need of multidisciplinary approach for the better management and improving the quality of life in patients with otalgia. The role of reassurance/psychotherapy should not be neglected beside the medical or surgical interventions in order to promote a holistic approach in health care system.

\section{Authors' Contribution}

Salman Baig and Sara Sadiq had designed the work, the acquisition and interpretation of data for the work.

Sara Sadiq did statistical analysis and drafted the work.

Salman Baig and Sara Sadiq revised it critically for important intellectual content.

\section{Conflicts of Interest}

The authors declare no conflicts of interest regarding the publication of this paper.

\section{References}

[1] Lieberman, E. and Redleaf, M.I. (2015) The Otalgia Point: A Novel Clinical Gesture in Otolaryngology. Annals of Otology, Rhinology \& Laryngology, 124, 953-956. https://doi.org/10.1177/0003489415593555

[2] Neilan, R.E. and Roland, P.S. (2010) Otalgia. Medical Clinics of North America, 94, 961-971. https://doi.org/10.1016/j.mcna.2010.05.004

[3] Lee, H.-J., et al. (2012) Korean Clinical Practice Guidelines: Otitis Media in Children. Journal of Korean Medical Science, 27, 835-848. https://doi.org/10.3346/jkms.2012.27.8.835

[4] Leung, A., Fong, J. and Leong, A.G. (2000) Otalgia in Children. Journal of the National Medical Association, 92, 254.

[5] Baig, S., et al. (2018) Impact of Multidisciplinary Team Approach to the Manage- 
ment of Otalgia Patients. The Pakistan Journal of Medicine and Dentistry, 7, 6-21.

[6] Kim, S.H., Kim, T.H., Byun, J.Y., Park, M.S. and Yeo, S.G. (2015) Clinical Differences in Types of Otalgia. Journal of Audiology \& Otology, 19, 34-38.

https://doi.org/10.7874/jao.2015.19.1.34

[7] The WHOQOL Group (1998) Development of the World Health Organization WHOQOL-BREF Quality of Life Assessment. Psychological Medicine, 28, 551-558. https://doi.org/10.1017/S0033291798006667

[8] Skevington, S.M., Lotfy, M. and O’Connell, K.A. (2004) The World Health Organization's WHOQOL-BREF Quality of Life Assessment: Psychometric Properties and Results of the International Field Trial. A Report from the WHOQOL Group. Quality of Life Research, 13, 299-310. https://doi.org/10.1023/B:QURE.0000018486.91360.00

[9] Martin, T., et al. (2015) The Cambridge Otology Quality of Life Questionnaire: An Otology-Specific Patient-Recorded Outcome Measure. A Paper Describing the Instrument Design and a Report of Preliminary Reliability and Validity. Clinical Otolaryngology, 40, 130-139. https://doi.org/10.1111/coa.12338

[10] Curriculum for Australian General Practice (RACGP) (2011) The RACGP Curriculum for Australian General Practice 2011.

[11] Holl, K., et al. (2015) The Impact of Childhood Acute Otitis Media on Parental Quality of Life in a Prospective Observational Cohort Study. Clinical Drug Investigation, 35, 613-624. https://doi.org/10.1007/s40261-015-0319-1

[12] Grindler, D.J., Blank, S.J., Schulz, K.A., Witsell, D.L. and Lieu, J.E.C. (2014) Impact of Otitis Media Severity on Children's Quality of Life. Otolaryngology-Head and Neck Surgery, 151, 333-340. https://doi.org/10.1177/0194599814525576

[13] Heidemann, C.H., et al. (2015) Quality-of-Life Differences among Diagnostic Subgroups of Children Receiving Ventilating Tubes for Otitis Media. Otolaryngology-Head and Neck Surgery, 153, 636-643. https://doi.org/10.1177/0194599815569491

[14] Richards, M. and Giannoni, C. (2002) Quality-of-Life Outcomes after Surgical Intervention for Otitis Media. Archives of Otolaryngology_Head \& Neck Surgery, 128, 776-782. https://doi.org/10.1001/archotol.128.7.776

[15] Mazlumoglu, M., Kuduban, O., Duksal, T., Cetin, A. and Sagsoz, M.E. (2017) Chronic Secondary Otalgia: Multidisciplinary Evaluation and Relationship with Cervical Spine Disease. International Journal of Otorhinolaryngology, 4, 3. https://doi.org/10.13188/2380-0569.1000017

[16] Chow, Y., Wabnitz, D. and Ling, J. (2008) Quality Of Life Outcomes After Ventilating Tube Insertion For Otitis Media in an Australian Population: Ps36. Anz Journal of Surgery, 78, A93.

[17] Chow, Y., Wabnitz, D.A. and Ling, J. (2007) Quality of Life Outcomes after Ventilating Tube Insertion for Otitis Media in an Australian Population. International Journal of Pediatric Otorhinolaryngology, 71, 1543-1547.

https://doi.org/10.1016/j.ijporl.2007.06.001

[18] Witsell, D.L., et al. (2005) The Cooperative Outcomes Group for ENT: A Multicenter Prospective Cohort Study on the Outcomes of Tympanostomy Tubes for Children with Otitis Media. Otolaryngology_Head and Neck Surgery, 132, 180-188. https://doi.org/10.1016/j.otohns.2004.11.004

[19] Baumann, I., Gerendas, B., Plinkert, P.K. and Praetorius, M. (2011) General and Disease-Specific Quality of Life in Patients with Chronic Suppurative Otitis Media-A Prospective Study. Health and Quality of Life Outcomes, 9, 48. 
https://doi.org/10.1186/1477-7525-9-48

[20] Choi, S.Y., et al. (2012) Factors Associated with Quality of Life after Ear Surgery in Patients with Chronic Otitis Media. Archives of Otolaryngology-Head \& Neck Surgery, 138, 840-845. https://doi.org/10.1001/archoto.2012.1800

[21] Jung, K.H., et al. (2010) Quality-of-Life Assessment after Primary and Revision Ear Surgery Using the Chronic Ear Survey. Archives of Otolaryngology - Head \& Neck Surgery, 136, 358-365. https://doi.org/10.1001/archoto.2010.24

[22] Swan, I., Guy, F. and Akeroyd, M. (2012) HealtH-Related Quality of Life Before and after Management in Adults Referred to Otolaryngology: A Prospective National Study. Clinical Otolaryngology, 37, 35-43.

https://doi.org/10.1111/j.1749-4486.2011.02433.x 